Turkish Journal of Geriatrics

DOI: $10.31086 /$ tigeri.2020.180

2020; 23(4): 424-433

\section{- Remziye Nur EKE ${ }^{1}$ (D) \\ - Mehmet ÖZEN ${ }^{1}$ iD \\ - Yasin ALTUN ${ }^{2}$ (D) \\ - Hamit Yaşar ELLIDAĞ}

CORRESPONDANCE

Remziye Nur Eke

University of Health Sciences, Antalya Training and Research Hospital, Family Medicine

Department, Antalya, Turkey

Phone: +05055018155

e-mail: drnureke@gmail.com

Received: May 12, 2020

Accepted: Nov 10, 2020

University of Health Sciences, Antalya Training and Research Hospital, Family Medicine Department, Antalya, Turkey

Serik Family Health Center No. 3, Family Medicine Unit, Antalya, Turkey

${ }^{3}$ University of Health Sciences, Antalya Training and Research Hospital,

Biochemistry Department, Antalya, Turkey

\title{
INVESTIGATION OF THE RELATIONSHIP BETWEEN MORTALITY AND RED CELL DISTRIBUTION WIDTH, MEAN PLATELET VOLUME, PLATELET-TO-LYMPHOCYTE RATIO, AND NEUTROPHIL-TO-LYMPHOCYTE RATIO IN GERIATRIC PATIENTS
}

\section{Abstract}

Introduction: This study aimed to investigate the relationship between allcause mortality and the values of red-cell distribution width, mean platelet volume, platelet-to-lymphocyte ratio, and neutrophil-to-lymphocyte ratio in geriatric patients who had become bedridden.

Materials and Method: The retrospective study reviewed 1981 patients aged 65-104 years who were bedridden and followed at University of Health Sciences, Antalya Training and Research Hospital Family Medicine Clinic from 2016 to 2018. Due to the effects on studied test parameters, patients with anemia were excluded from the study, and 898 patients included. The baseline variables red cell distribution width, mean platelet volume, platelet-to-lymphocyte ratio, and neutrophil-tolymphocyte ratio were compared between survivors and non-survivors.

Results: Of the 898 patients, 141 (15.7\%) died during follow-up. Mean red cell distribution width (15.7\%), platelet-to-lymphocyte ratio (140.5), and neutrophilto-lymphocyte ratio (3.14) levels in non-survivors were statistically significantly higher than those of survivors (14.9\%, $p<0.001 ; 125, p=0.030$; and 2.38, $p<0.001$, respectively). The retrospective follow-up revealed that red cell distribution width, platelet-to-lymphocyte ratio and neutrophil-to-lymphocyte ratio levels (17.6\%, 205.82, and 4.99, respectively) had increased during the last three months before death, but this was not statistically significant. The results of univariate logistic regression analyses showed that mortality was positively associated with red cell distribution width and neutrophil-to-lymphocyte ratio. In a multivariate model, red cell distribution width was identified as an independent predictive factor associated with mortality.

Conclusion: Red cell distribution width, platelet-to-lymphocyte ratio, and neutrophil-to-lymphocyte ratio may be strong predictors of mortality in patients who have become bedridden, and alarms to take action for measures. Aged

Keywords: Erythrocytes; Neutrophils; Lymphocytes; Blood Platelets; Mortality; 


\section{INTRODUCTION}

Red blood cell distribution width (RDW), mean platelet volume (MPV), and neutrophil, lymphocyte, and platelet (PLT) counts are inexpensive and rapid tests routinely used in clinical practice as part of a complete blood count (CBC), which have great potential as prognostic markers. RDW is a quantitative measure of variability in the size of circulating erythrocytes. Higher values reflect greater heterogeneity in cell sizes and indicate anisocytosis (1). Although the mechanism explaining the relationship between RDW and survival is not fully understood, it is believed that systemic factors affecting erythrocyte homeostasis such as inflammation and oxidative stress may be responsible (2). Like RDW, others such as MPV, platelet-to-lymphocyte ratio (PLR), and neutrophil-to-lymphocyte ratio (NLR) are novel inflammatory markers that are indicative of systemic inflammation (3-5). MPV reflects mean platelet size and larger platelets are more active than functionally, metabolically, and enzymatically smaller ones. Platelets with a larger volume contain more prothrombotic material, and increased MPV indicates increased platelet production and activation. Platelet activation is associated with adverse clinical outcomes of vascular diseases such as coronary artery disease, stroke, and venous thromboembolism (6). In the setting of cancer, NLR, PLR, and RDW are biomarkers indicating systemic inflammation and are considered as early diagnostic and prognostic factors $(7,8)$. Inflammatory cells, chemokines, cytokines, and proinflammatory mediators that play a role in inflammation in cancer-related mortality contribute to tumor cell formation, proliferation and metastasis (9). Similarly, inflammation accounts for the atherosclerotic process and mortality associated with cardiovascular diseases. Atherosclerotic plaques are thought to develop as an inflammatory response to vascular injury $(10,11)$. As a result, inflammation is the most prominent mechanism behind all-cause mortality, particularly in vascular diseases such as cardiovascular diseases, stroke, and venous thromboembolism as well as cancerrelated mortality and this process can be assessed by tests such as RDW, MPV, PLR, and NLR, which are very simple.

Several studies have reported that RDW, MPV, PLR, and NLR are strong predictors of mortality. For example, high RDW was associated with increased mortality in patients with acute heart failure in a study by Van Kimmenade (12), in patients with communityacquired intra-abdominal sepsis followed up in the intensive care unit in a study by Özdogan (13), and in patients older than 65 years presenting to the emergency department in a study by Soo Hyun Kim (14). On the other hand, in their meta-analysis of 11 cohort studies Tajarernmuang et al. reported MPV as the predictor of all-cause mortality for noncardiac critically ill patients (6), while Bozkurt et al. reported MPV and NLR as the predictor of all-cause mortality in geriatric patients followed up in the intensive care unit, and Wang et al. reported NLR as the predictor of all-cause mortality in a metaanalysis of 10 cohort studies $(3,15)$.

Despite all these studies, large scale and followup studies are still needed to fully understand the effect of RDW, MPV, PLR, and NLR on mortality. To this end, this study aimed to investigate the relationship of RDW, MPV, PLR, and NLR with mortality in geriatric patients who had become bedridden due to various diseases.

\section{MATERIALS AND METHOD}

\section{Study population}

The retrospective study reviewed a population of 1981 patients aged 65-104 years who were bedridden and followed at the University of Health Sciences, Antalya Training and Research Hospital (TRH) Family Medicine Clinic between January 1, 2016 and December 31, 2018. The patients' laboratory test results were obtained from the hospital's information management system. Patients with anemia (The World Health Organization defined 
Table 1. Comparison of study parameters and laboratory data between groups

\begin{tabular}{|c|c|c|c|c|c|}
\hline \multicolumn{2}{|c|}{ Variables } & $\begin{array}{c}\text { Total } \\
(n=898)\end{array}$ & $\begin{array}{l}\text { Survivors } \\
(n=757)\end{array}$ & $\begin{array}{l}\text { Non-survivors } \\
\quad(n=141)\end{array}$ & $p$ \\
\hline \multicolumn{2}{|l|}{ Age } & 79 (19-104) & 78 (19-104) & $83(24-103)$ & $<0.001$ \\
\hline \multirow{2}{*}{ Gender } & Female & $599(66.7)$ & $505(66.7)$ & $94(66.7)$ & 0.992 \\
\hline & Male & $299(33.3)$ & $252(33.3)$ & 47 (33.3) & \\
\hline \multirow{6}{*}{ Diagnoses } & Cancer & $55(6.1)$ & $35(4.6)$ & $20(14.2)$ & $<0.001$ \\
\hline & DM & $100(11.1)$ & $90(11.9)$ & $10(7.1)$ & 0.096 \\
\hline & Alzheimer & $167(18.6)$ & $133(17.6)$ & $34(24.1)$ & 0.067 \\
\hline & CVD & $218(24.3)$ & $187(24.7)$ & $31(22)$ & 0.490 \\
\hline & CVS diseases & $285(31.7)$ & $247(32.6)$ & $38(27)$ & 0.183 \\
\hline & Lung diseases & $37(4.1)$ & $36(4.8)$ & $1(0.7)$ & 0.026 \\
\hline \multirow{8}{*}{$\begin{array}{l}\text { Mean values of study } \\
\text { parameters }\end{array}$} & HGB (g/dL) & $13.5 \pm 1.11(10-18.6)$ & $13.6 \pm 1.1(10-18.6)$ & $13.25 \pm 1(12-16.7)$ & 0.004 \\
\hline & НCT (\%) & 41 (31.7-58.5) & $41(31.7-58.5)$ & $41.2(36.6-51.8)$ & 0.417 \\
\hline & WBC $(103 / \mathrm{mm} 3)$ & $7.5(2.1-22.5)$ & $7.4(2.1-22)$ & $8.2(3.2-22.5)$ & 0.002 \\
\hline & PLT (103/mm3) & $232(37-1071)$ & $232(52-1071)$ & 227 (37-542) & 0.965 \\
\hline & RDW (\%) & $15.1(12.1-28.9)$ & $14.9(12.1-28.9)$ & $15.7(12.6-26)$ & $<0.001$ \\
\hline & MPV $(\mu \mathrm{m} 3)$ & $8.99 \pm 1.25(6-13.6)$ & $8.98 \pm 1.24(6-13.6)$ & $9.04 \pm 1.3(6.3-12.8)$ & 0.584 \\
\hline & PLR & $127.74(29.3-1750)$ & 125 (29.3-1750) & $140.5(35.43-805)$ & 0.030 \\
\hline & NLR & $2.5(0.11-70.5)$ & $2.38(0.11-47.4)$ & $3.14(0.64-70.5)$ & $<0.001$ \\
\hline \multirow{4}{*}{$\begin{array}{l}\text { Study parameters } \\
\text { above the upper limits }\end{array}$} & RDW>16,5 (\%) & $185(20.6)$ & $139(18.4)$ & $46(32.6)$ & $<0.001$ \\
\hline & MPV $>10,5(\mu \mathrm{m} 3)$ & $118(13.1)$ & 99 (13.1) & 19 (13.5) & 0.898 \\
\hline & PLR $>132.5$ & $418(46.5)$ & $338(44.6)$ & $80(56.7)$ & 0.008 \\
\hline & NLR $>1.77$ & $660(73.5)$ & $546(72.1)$ & $114(80.9)$ & 0.031 \\
\hline
\end{tabular}

Data are presented as $\mathrm{n}(\%)$, mean \pm SD (min-max) and median (min-max). Mann-Whitney U test, Student t test, Pearson Chi-Square test. DM: Diabetes mellitus, CVD: Cerebrovascular diseases, CVS: Cardiovascular system, HGB: Hemoglobin, HCT: Hematocrit, WBC: White blood cells, PLT: Platelet, RDW: Red cell distribution width, MPV: Mean platelet volume, PLR: Platelet-to-lymphocyte ratio, NLR: Neutrophil-to-lymphocyte ratio.

anemia as serum hemoglobin levels of $<13 \mathrm{~g} / \mathrm{dL}$ in men over 15 years of age, $<12 \mathrm{~g} / \mathrm{dL}$ in women over 15 years of age and in non-pregnant women, and $<11 \mathrm{~g} / \mathrm{dL}$ in pregnant women), were excluded, as anemia may affect the study parameters. The clinical data of 898 patients were examined from patients' files. The Antalya TRH Clinical Research Ethics Committee approved the study prior to its implementation (approval no; 8/20, date; 07 March 2019), and the study was performed in compliance with the Declaration of Helsinki.

\section{Data collection and laboratory measurements}

The demographic data, diagnoses, mortality, and $\mathrm{CBC}$ parameters of the patients were recorded on previously developed forms.

CBC parameters (hemogram) were analyzed using a Beckman Coulter LH 780 Hematology Analyzer (Beckman Coulter Inc., Miami, Florida). The NLR was calculated by dividing the number of neutrophils with the number of lymphocytes, and the PLR by dividing the number of platelets with the number of lymphocytes.

The normal distribution ranges for RDW, MPV, PLR, and NLR vary, but have been reported as approximately 12-16\%; 9.5-11.5 بm3; 125-135, and $1.50-2.0$, respectively, in a variety of studies (2, 16-19). 
Table 2. Comparison of patients according to RDW and MPV values

\begin{tabular}{|c|c|c|c|c|c|c|c|}
\hline \multicolumn{2}{|c|}{ Variables } & $\begin{array}{c}R D W \leq 16,5 \\
(n=713)\end{array}$ & $\begin{array}{c}\text { RDW }>16,5 \\
(n=185)\end{array}$ & $p$ & $\begin{array}{c}M P V \leq 10,4 \\
(n=780)\end{array}$ & $\begin{array}{c}M P V>10,5 \\
(n=118)\end{array}$ & $p$ \\
\hline \multicolumn{2}{|l|}{ Age } & $78(19-104)$ & $81(22-104)$ & 0.005 & $79(19-104)$ & 78 (20-96) & 0.077 \\
\hline \multirow{2}{*}{ Gender } & Female & $460(64.5)$ & $139(75.1)$ & \multirow{2}{*}{0.006} & $517(66.3)$ & 82 (69.5) & \multirow{2}{*}{0.491} \\
\hline & Male & $253(35.5)$ & $46(24.9)$ & & $263(33.7)$ & $36(30.5)$ & \\
\hline \multirow{6}{*}{ Diagnoses } & Cancer & $40(5.6)$ & $15(8.1)$ & 0.207 & $49(6.3)$ & $6(5.1)$ & \\
\hline & DM & 78 (10.9) & $22(11.9)$ & 0.714 & $86(11)$ & $14(11.9)$ & 0.613 \\
\hline & Alzheimer & $138(19.4)$ & $29(15.7)$ & 0.252 & 145 (18.6) & 22 (18.6) & 0.787 \\
\hline & CVD & $174(24.4)$ & $44(23.8)$ & 0.861 & $189(24.2)$ & $29(24.6)$ & 0.989 \\
\hline & CVS diseases & $225(31.6)$ & $60(32.4)$ & 0.820 & $253(32.4)$ & $32(27.1)$ & 0.935 \\
\hline & Lung diseases & $28(3.9)$ & $9(4.9)$ & 0.567 & $26(3.3)$ & $11(9.3)$ & 0.247 \\
\hline \multicolumn{2}{|l|}{$\mathrm{HGB}(\mathrm{g} / \mathrm{dL})$} & $\begin{array}{l}13.57 \pm 1.13 \\
(10-18.6)\end{array}$ & $\begin{array}{l}13.22 \pm 0.94 \\
(12-16.7)\end{array}$ & $<0.001$ & $\begin{array}{l}13.45 \pm 1.06 \\
(12-18.6)\end{array}$ & $\begin{array}{l}13.86 \pm 1.32 \\
(10-18.5)\end{array}$ & 0.001 \\
\hline \multicolumn{2}{|l|}{ HCT (\%) } & 41 (31.7-58.5) & $40.9(35-51.4)$ & 0.868 & $40.8(35-58.5)$ & $42(31.7-56.4)$ & $<0.001$ \\
\hline \multicolumn{2}{|c|}{ WBC (103/mm3) } & $7.4(2.1-22.5)$ & $7.9(3.8-22.4)$ & 0.008 & $7.4(2.1-22.5)$ & 8.19 (3.3-22) & 0.018 \\
\hline \multicolumn{2}{|c|}{ PLT (103/mm3) } & 228 (65-598) & $245(37-1071)$ & 0.011 & 237.5 (65-1071) & $183(37-747)$ & $<0.001$ \\
\hline \multicolumn{2}{|l|}{ RDW (\%) } & $14.7(12.1-16.5)$ & $17.6(16.6-28.9)$ & $<0.001$ & $15.1(12.1-26)$ & $14.8(12.4-28.9)$ & 0.886 \\
\hline \multicolumn{2}{|l|}{$\mathrm{MPV}(\mu \mathrm{m} 3)$} & $\begin{array}{l}8.95 \pm 1.24 \\
(6.2-13.4) \\
\end{array}$ & $\begin{array}{l}9.12 \pm 1.31 \\
(6-13.6) \\
\end{array}$ & 0.110 & $\begin{array}{l}8.64 \pm 0.91 \\
(6-10.4) \\
\end{array}$ & \begin{tabular}{|l}
$11.26 \pm 0.7$ \\
$(10.5-13.6)$ \\
\end{tabular} & $<0.001$ \\
\hline \multicolumn{2}{|l|}{ PLR } & $124.3(29.3-805)$ & $140(33.7-1750)$ & 0.016 & \begin{tabular}{|l}
$132.4(29.3-$ \\
$1750)$
\end{tabular} & 93.8 (30.7-315.5) & $<0.001$ \\
\hline \multicolumn{2}{|l|}{ NLR } & $2.4(0.11-70.5)$ & $2.67(0.5-47.43)$ & 0.013 & $2.46(0.11-70.5)$ & $2.68(0.6-15.7)$ & 0.408 \\
\hline \multirow{2}{*}{$\begin{array}{l}\text { Mortality } \\
\text { status }\end{array}$} & Survivors & $618(86.7)$ & $139(75.1)$ & \multirow{2}{*}{$<0.001$} & $658(84.4)$ & 99 (83.9) & \multirow{2}{*}{0.898} \\
\hline & Non-survivors & 95 (13.3) & $46(24.9)$ & & $122(15.6)$ & $19(16.1)$ & \\
\hline
\end{tabular}

Data are presented as $\mathrm{n}(\%)$, mean \pm SD (min-max) and median (min-max). Mann-Whitney U test, Student t test, Pearson Chi-Square test, Fisher's Exact test. DM: Diabetes mellitus, CVD: Cerebrovascular diseases, CVS: Cardiovascular system, HGB: Hemoglobin, HCT: Hematocrit, WBC: White blood cells, RDW: Red cell distribution width, MPV: Mean platelet volume, PLR: Platelet-to-lymphocyte ratio, NLR: Neutrophil-to-lymphocyte ratio.

Similar to those in the literature, the normal intervals were identified in this study by our hospital laboratory as $11.5-16.5 \% ; 7.4-10.4 \mu \mathrm{m} 3 ; 107.77-$ 132.5, and 1.5-1.77 for RDW, MPV, PLR, and NLR, respectively.

\section{Statistical Analysis}

Statistical analyses were made using IBM SPSS Statistics for Windows, Version 23.0 (IBM Corp., Armonk, NY, USA). Pearson chi-square and Fisher's exact tests were performed for categorical variables. Conformity of the data to normal distribution was assessed with the Shapiro-Wilk test. MannWhitney $U$ tests and Student's $t$ tests were used for analysis of non-normally and normally distributed numerical data, respectively. For nonparametric variables Kruskal-Wallis tests were used to compare between groups and Bonferroni-Dunn tests were used as a post-hoc test for significant cases, while for parametric variables one-way ANOVA with post-hoc Tukey HSD tests were used. To compare previous measurements with those in the last three months, paired t-tests were used for the parametric data, and Wilcoxon signed-ranks tests were used for nonparametric data. Spearman and Pearson correlations were applied to investigate the correlation between continuous variables. Univariate and multivariate logistic regression 
Table 3. Comparison of patients according to PLR and NLR values

\begin{tabular}{|c|c|c|c|c|c|c|c|}
\hline \multicolumn{2}{|c|}{ Variables } & $\begin{array}{c}\text { PLR } \leq 132,5 \\
(n=480)\end{array}$ & $\begin{array}{c}\text { PLR>132,5 } \\
(n=418)\end{array}$ & $p$ & $\begin{array}{c}N L R \leq 1,77 \\
(n=238)\end{array}$ & $\begin{array}{c}\text { NLR>1,77 } \\
(n=660)\end{array}$ & $p$ \\
\hline \multicolumn{2}{|l|}{ Age } & 78 (19-104) & $80(19-99)$ & 0.002 & $76(20-104)$ & $79(19-102)$ & 0.002 \\
\hline \multirow{2}{*}{ Gender } & Female & $307(64)$ & $292(69.9)$ & \multirow{2}{*}{0.061} & $169(71)$ & $430(65.2)$ & \multirow{2}{*}{0.100} \\
\hline & Male & $173(36)$ & $126(30.1)$ & & $69(29)$ & $230(34.8)$ & \\
\hline \multirow{6}{*}{ Diagnoses } & Cancer & $29(6)$ & $26(6.2)$ & 0.911 & $14(5.9)$ & $41(6.2)$ & 0.856 \\
\hline & DM & $44(9.2)$ & $56(13.4)$ & 0.044 & $22(9.2)$ & $78(11.8)$ & 0.279 \\
\hline & Alzheimer & $101(21)$ & $66(15.8)$ & 0.044 & $49(20.6)$ & 118 (17.9) & 0.357 \\
\hline & CVD & $113(23.5)$ & $105(25.1)$ & 0.582 & $63(26.5)$ & $155(23.5)$ & 0.357 \\
\hline & CVS diseases & $148(30.8)$ & $137(32.8)$ & 0.533 & $72(30.3)$ & $213(32.3)$ & 0.566 \\
\hline & Lung diseases & $23(4.8)$ & $14(3.3)$ & 0.278 & $16(6.7)$ & $21(3.2)$ & 0.018 \\
\hline \multicolumn{2}{|l|}{$\mathrm{HGB}(\mathrm{g} / \mathrm{dL})$} & $\begin{array}{l}13.62 \pm 1.13 \\
(12-18.6)\end{array}$ & $\begin{array}{l}13.36 \pm 1.06 \\
(10-16.9) \\
\end{array}$ & 0.001 & $\begin{array}{l}13.52 \pm 1.03 \\
(12-18.3)\end{array}$ & $\begin{array}{l}13.49 \pm 1.13 \\
(10-18.6)\end{array}$ & 0.786 \\
\hline \multicolumn{2}{|l|}{ HCT (\%) } & $41.2(35.4-58.5)$ & $40.7(31.7-51.8)$ & 0.005 & 41.15 (35-52.9) & 41 (31.7-58.5) & 0.640 \\
\hline \multicolumn{2}{|c|}{ WBC (103/mm3) } & 7.7 (3.2-22.4) & $7.4(2.1-22.5)$ & 0.158 & $6.5(3.2-15.7)$ & $7.9(2.1-22.5)$ & $<0.001$ \\
\hline \multicolumn{2}{|c|}{ PLT (103/mm3) } & 209 (37-471) & $264(101-1071)$ & $<0.001$ & 224 (98-1071) & 234 (37-947) & 0.022 \\
\hline \multicolumn{2}{|l|}{ RDW (\%) } & $14.8(12.1-24.4)$ & $15.3(12.3-28.9)$ & $<0.001$ & $14.8(12.3-24.4)$ & $15.1(12.1-28.9)$ & 0.004 \\
\hline \multicolumn{2}{|l|}{ MPV $(\mu \mathrm{m} 3)$} & $\begin{array}{l}9.31 \pm 1.25 \\
(6.3-13.4) \\
\end{array}$ & $\begin{array}{l}8.62 \pm 1.15 \\
(6-13.6) \\
\end{array}$ & $<0.001$ & $\begin{array}{l}9.01 \pm 1.21 \\
(6.3-13.1) \\
\end{array}$ & \begin{tabular}{|l}
$8.98 \pm 1.27$ \\
$(6-13.6)$ \\
\end{tabular} & 0.778 \\
\hline \multicolumn{2}{|l|}{ PLR } & $\begin{array}{l}97.8 \\
(29.3-132.5)\end{array}$ & $\begin{array}{l}171 \\
(132.6-1750) \\
\end{array}$ & $<0.001$ & $\begin{array}{l}93.8 \\
(29.3-428.4)\end{array}$ & \begin{tabular}{|l}
142.2 \\
$(30.7-1750)$ \\
\end{tabular} & $<0.001$ \\
\hline \multicolumn{2}{|l|}{ NLR } & $1.96(0.5-14.9)$ & $3.4(0.1-70.5)$ & $<0.001$ & $1.42(0.11-1.77)$ & $3.06(1.78-70.5)$ & $<0.001$ \\
\hline \multirow{2}{*}{$\begin{array}{l}\text { Mortality } \\
\text { status }\end{array}$} & Survivors & 419 (87.3) & 338 (80.9) & \multirow{2}{*}{0.008} & 211 (88.7) & $546(82.7)$ & \multirow{2}{*}{0.031} \\
\hline & Non-survivors & $61(12.7)$ & 80 (19.1) & & 27 (11.3) & $114(17.3)$ & \\
\hline
\end{tabular}

Data are presented as $\mathrm{n}(\%)$, mean $\pm \mathrm{SD}$ (min-max) and median (min-max). Mann-Whitney U test, Student t test, Pearson Chi-Square test, Fisher's Exact test. DM: Diabetes mellitus, CVD: Cerebrovascular diseases, CVS: Cardiovascular system, HGB: Hemoglobin, HCT: Hematocrit, WBC: White blood cells, PLT: Platelet, RDW: Red cell distribution width, MPV: Mean platelet volume, PLR: Platelet-to-lymphocyte ratio, NLR: Neutrophil-to-lymphocyte ratio.

analysis was used to determine independent risk factors associated with mortality. The variables which showed significant association with mortality in the univariate analyses were further tested in the multivariate model. Data are expressed as $\mathrm{n}(\%)$, mean \pm standard deviation or median (min-max), as appropriate. $P$ values $<0.05$ were considered statistically significant.

\section{RESULTS}

The study included 898 patients, 299 of whom were male (33.3\%) and 599 of whom were female (66.7\%). The mean age of the patients was $79(65-104)$ years.
Of the patients, 757 were survivor and 141 were nonsurvivor. The mean follow-up period of the patients was calculated as $19 \pm 10,5$ (3-52) months. Of the patients, 285 (31.7\%) had cardiovascular system (CVS) disease, 218 (24.3\%) had cerebrovascular disease (CVD), and 167 (18.6\%) had Alzheimer's disease. The rate of non-survival was significantly higher in patients with cancer $(\mathrm{p}<0.001)$. The mean levels of RDW (15.7\%), PLR (140.5), and NLR (3.14) in non-survivors were statistically significantly higher than those in survivors $(14.9 \%, p<0.001 ; 125, p=$ 0.030 , and $2.38 p<0.001$ ), respectively (Table 1).

Based on the guidance of our hospital laboratory, the upper normal limits for RDW, MPV, PLR, and 
Table 4. Correlation between RDW and MPV levels and other factors in survivor and non-survivor patients

\begin{tabular}{|c|c|c|c|c|c|c|c|c|}
\hline \multirow{3}{*}{$\begin{array}{c}\text { Study } \\
\text { parameters }\end{array}$} & \multicolumn{4}{|c|}{ RDW } & \multicolumn{4}{|c|}{ MPV } \\
\hline & \multicolumn{2}{|c|}{$\begin{array}{l}\text { Survivor } \\
(n=757)\end{array}$} & \multicolumn{2}{|c|}{$\begin{array}{c}\text { Non-Survivor } \\
(n=141)\end{array}$} & \multicolumn{2}{|c|}{$\begin{array}{l}\text { Survivor } \\
(n=757)\end{array}$} & \multicolumn{2}{|c|}{$\begin{array}{c}\text { Non-Survivor } \\
(n=141)\end{array}$} \\
\hline & $r$ & $p$ & $\mathbf{r}$ & $p$ & $r$ & $p$ & $r$ & $p$ \\
\hline Age & 0.222 & $<0.001$ & 0.070 & 0.408 & -0.030 & 0.417 & 0.065 & 0.442 \\
\hline $\mathrm{HGB}(\mathrm{g} / \mathrm{dL})$ & -0.245 & $<0.001$ & -0.090 & 0.290 & 0.087 & 0.016 & 0.116 & 0.171 \\
\hline HCT (\%) & -0.097 & 0.007 & 0.094 & 0.268 & 0.108 & 0.003 & 0.098 & 0.249 \\
\hline WBC (103/mm3) & 0.068 & 0.061 & 0.255 & 0.002 & 0.143 & $<0.001$ & -0.031 & 0.715 \\
\hline PLT (103/mm3) & 0.046 & 0.211 & 0.204 & 0.015 & -0.355 & $<0.001$ & -0.330 & $<0.001$ \\
\hline $\mathrm{MPV}(\mu \mathrm{m} 3)$ & 0.013 & 0.725 & 0.021 & 0.808 & - & - & - & - \\
\hline RDW (\%) & - & - & - & - & 0.013 & 0.725 & 0.021 & 0.808 \\
\hline PLR & 0.108 & 0.003 & 0.086 & 0.309 & -0.353 & $<0.001$ & -0.275 & 0.001 \\
\hline NLR & 0.127 & $<0.001$ & 0.162 & 0.054 & -0.028 & 0.440 & -0.01 & 0.907 \\
\hline
\end{tabular}

Spearman correlation test. HGB: Hemoglobin, HCT: Hematocrit, RDW: Red cell distribution width, WBC: White blood cells, PLT: Platelet, MPV: Mean platelet volume, PLR: Platelet-to-lymphocyte ratio, NLR: Neutrophil-to-lymphocyte ratio.

NLR were established as 16.5\%, $10.4 \mu \mathrm{m} 3,132.5$, and 1.77 , respectively. Of the 141 non-survivors, 46 (32.6\%) had RDW>16.5\%, 80 (56.7\%) had PLR>132.5, and 114 (80.9\%) had NLR>1.77, which were all significantly higher than the survivor patients (Table 1).

On comparing the patients according to RDW, MPV, PLR, and NLR values in terms of demographic and laboratory characteristics, the ratio of survivor patients (86.7\%) with RDW $\leq 16.5$ was found to be statistically significantly higher than those who died (13.3\%) $(p<0.001)$. Similarly, the rates of PLR $\leq 132.5$ (87.3\%, $p=0.008)$ and NLR $\leq 1.77$ (82.7\%, $(p=0.031)$ were found to be statistically significantly higher in survivors than those who died (Table 2, 3).

Although the mean RDW (16\%), MPV $(9.39 \pm 1.69$ $\mu \mathrm{m3})$, PLR (154.2), and NLR (4.45) levels of the 141 patients who died in the retrospective evaluation were not statistically significant, the highest rates were found in the patients who were tested in the last month before death. On comparing the relationship of the study parameters of 36 patients who had CBC in the last three months and more than three months before death $(16.5 \%, 156.67$, and 3.7, respectively), the mean RDW, PLR, and NLR levels
(17.6\%, 205.82, and 4.99, respectively) were found to have increased in the last three months before death, but this was not statistically significant.

A positive but weak correlation was observed between RDW levels and age $(r=0.222, p<0.001)$, PLR $(r=0.108, p=0.003)$, and NLR $(r=0.127, p<0.001)$ in survivors. RDW levels also negatively correlated with HGB $(r=-0.245, p<0.001)$ and hematocrit $(H C T)$ ( $r=-0.097, p=0.007)$ in survivors. In non-survivors, RDW levels positively correlated with white blood cell (WBC) count $(r=0.255, p=0.002)$ and PLT $(r=0.204, p=0.015)$ (Table 4).

In survivors, MPV levels positively correlated with HGB $(r=0.087, p=0.016), \mathrm{HCT} \quad(r=0.108$, $p=0.003)$, and WBC ( $r=0.143, p<0.001)$, and also negatively correlated with PLT $(r=-0.355, p<0.001)$ and PLR $(r=-0.353, p<0.001)$. A negative but weak correlation was observed between MPV and PLT $(r=-0.330, p<0.001)$ and PLR $(r=-0.275, p=0.001)$ in non-survivors (Table 4).

The results of univariate logistic regression analyses showed that mortality was positively associated with age (odds ratio, [OR]: 1.03; 95\% confidence interval $[\mathrm{Cl}]$ : 1.016-1.043; $p<0.001)$, cancer (OR: 3.41; 95\% Cl: 1.905-6.103; $p<0.001$ ), 
Table 5. Logistic regression analysis of the mortality predictors

\begin{tabular}{|c|c|c|c|c|c|}
\hline \multirow{2}{*}{\multicolumn{2}{|c|}{ Variables }} & \multicolumn{2}{|c|}{ Univariate logistic regression } & \multicolumn{2}{|c|}{ Multiple logistic regression } \\
\hline & & OR $(95 \% \mathrm{Cl})$ & $p$ value & OR $(95 \% \mathrm{Cl})$ & $p$ \\
\hline \multicolumn{2}{|l|}{ Age } & $1.03(1.016-1.043)$ & $<0.001$ & $1.027(1.012-1.041)$ & $<0.001$ \\
\hline \multicolumn{2}{|c|}{ Gender (Ref= female) } & $1.002(0.684-1.467)$ & 0.992 & - & - \\
\hline \multirow{6}{*}{ Diagnoses } & Cancer & $3.41(1.905-6.103)$ & $<0.001$ & $3.189(1.716-5.926)$ & $<0.001$ \\
\hline & Diabetes mellitus & $0.566(0.287-1.116)$ & 0.100 & - & - \\
\hline & Alzheimer & $1.491(0.971-2.289)$ & 0.068 & - & - \\
\hline & CVD & $0.859(0.558-1.322)$ & 0.490 & - & - \\
\hline & CVS diseases & $0.762(0.51-1.139)$ & 0.184 & - & - \\
\hline & Lung diseases & $0.143(0.019-1.052)$ & 0.056 & - & - \\
\hline \multicolumn{2}{|l|}{$\mathrm{HGB}(\mathrm{g} / \mathrm{dL})$} & $0.765(0.638-0.917)$ & 0.004 & $0.882(0.726-1.071)$ & 0.206 \\
\hline \multicolumn{2}{|l|}{ HCT (\%) } & $1.009(0.956-1.065)$ & 0.734 & - & - \\
\hline \multicolumn{2}{|l|}{ WBC (103/mm3) } & $1.152(1.083-1.226)$ & $<0.001$ & $1.102(1.027-1.182)$ & 0.007 \\
\hline \multicolumn{2}{|l|}{ PLT (103/mm3) } & $1(0.998-1.002)$ & 0.711 & - & - \\
\hline \multicolumn{2}{|l|}{ RDW (\%) } & $1.209(1.114-1.312)$ & $<0.001$ & $1.132(1.033-1.239)$ & 0.008 \\
\hline \multicolumn{2}{|l|}{$\mathrm{MPV}(\mu \mathrm{m} 3)$} & $1.04(0.903-1.199)$ & 0.584 & - & - \\
\hline \multicolumn{2}{|l|}{ PLR } & $1.002(1-1.003)$ & 0.074 & - & - \\
\hline \multicolumn{2}{|l|}{ NLR } & $1.142(1.066-1.223)$ & $<0.001$ & $1.053(0.997-1.113)$ & 0.064 \\
\hline
\end{tabular}

CVD: Cerebrovascular diseases, CVS: Cardiovascular system, HGB: Hemoglobin, HCT: Hematocrit, WBC: White blood cells, PLT: Platelet, RDW: Red cell distribution width, MPV: Mean platelet volume, PLR: Platelet-to-lymphocyte ratio, NLR: Neutrophil-to-lymphocyte ratio.

WBC (OR: 1.152; 95\% Cl: 1.083-1.226; $\mathrm{p}<0.001$ ), RDW (OR: 1.209; 95\% Cl: 1.114-1.312; $\mathrm{p}<0.001$ ), and NLR (OR: 1.142; 95\% Cl: 1.066-1.223; $p<0.001$ ), while it was negatively associated with HGB (OR: 0.765; 95\% Cl: 0.638-0.917; $p=0.004$ ) (Table 5).

In a multivariate model, age (OR: $1.027 ; 95 \%$ Cl: $1.012-1.041 ; p<0.001)$, cancer (OR: 3.189; $95 \%$ Cl: $1.716-5.926 ; p<0.001)$, WBC (OR: 1.102; 95\% $\mathrm{Cl}$ : 1.027-1.182; $p=0.007$ ), and RDW (OR: 1.132; 95\% Cl: 1.033-1.239; $p=0.008)$ were identified as independent predictive factors associated with mortality (Table 5).

\section{DISCUSSION}

In this study, we found that in patients who had become bedridden, higher RDW, PLR, and NLR levels were significantly associated with higher mortality risk. We did not find any correlation between MPV levels and mortality. In addition, we found that mortality positively correlated with age, cancer, WBC, RDW, and NLR, while it negatively correlated with HGB, and that RDW was an independent predictive factor related to mortality. In this retrospective follow-up, we also found that RDW, MPV, PLR, and NLR were highest in the last month before death, and that RDW, PLR, and NLR values increased in the last three months in patients who had undergone multiple examinations.

The effects of diseases such as cancer, cardiovascular diseases, and cerebrovascular diseases on the study parameters have not been determined definitely. It is thought that the most accepted common mechanism may be inflammation. In this study, it was aimed to determine the relationship between study parameters and mortality due to all causes (cancer, cardiovascular diseases, cerebrovascular diseases, etc.). For this 
reason, cancer patients as well as patients with cardiovascular and cerebrovascular diseases in particular, were included in the study.

The relationship between elevated RDW, MPV, PLR, and NLR levels and increased risk of mortality has been previously reported in various patient groups (such as middle-aged and elderly patients, critically ill patients, patients presenting to the emergency department, or special diagnostic groups such as patients with coronary artery stenos, acute myocardial infarction, or chronic kidney disease) $(2,6,13-15,17,20)$. However, to our knowledge there has been no study in which these four inflammatory markers were evaluated in patients who had become bedridden.

Many studies have investigated the relationship of high RDW to increased risk of mortality. For instance, Kushang et al. analyzed seven populationbased studies and demonstrated that high RDW values were associated with increased mortality risk. This study found that every $1 \%$ increase in RDW increased the total mortality risk by $14 \%$. Moreover, RDW was found to be strongly associated with CVD, cancers, and other disease-related deaths as well as total mortality even in patients without age-related disease (1). In a study conducted by Patel et al. with 8175 adults aged 45 and over showed that each $1 \%$ increase in RDW increased the risk of mortality by $22 \%$ and that RDW is strongly associated with mortality even in non-anemic participants (2). Only non-anemic patients were evaluated in our study, in which mean RDW levels of non-survivors were found to be significantly higher than those of the survivors, and univariate logistic regression analysis showed a strong relationship between RDW and mortality, whereas multivariate logistic regression analysis showed that RDW was an independent risk factor of mortality.

Wang et al. studied 134 patients with adenosquamous carcinoma of the lung and reported that high PLR levels were independently associated with low survival rate (21). Likewise, Oylumlu et al. found that PLR values greater than 142 predicted in-hospital deaths in patients with acute coronary syndrome (20). In our study, mean PLR levels of non-survivors were found to be significantly higher (140.5) than those of the survivors (125).

Tamhane et al. studied 2833 patients presenting with acute coronary syndrome and stated that the level of NLR measured at admission was an independent predictor of in-hospital and six-month mortality (22). Liu et al. reported that $80 \%$ of 333 patients with sepsis died within 28 days, and NLR was found to be significantly higher in patients who died (23). A similar study in patients with sepsis and septic shock reported that high NLR was predictive of 28 day mortality (24). Similarly, in our study, the highest levels of NLR were found in the last month before death in non-survivors, and NLR levels increased in the last three months prior to death in non-survivor patients with multiple examinations.

In a study by Yoldas, in which PLR and NLR were evaluated together as a marker of mortality, NLR and PLR levels of non-survivors were found to be significantly higher than those of survivors (25). In our study, in addition to RDW and MPV, PLR and NLR were evaluated as markers of all-cause mortality in patients who had become bedridden, and mean PLR, and NLR levels were found to be significantly higher in non-survivor patients compared to survivors.

Iron, ferritin, vitamin B12 and folic acid deficiencies can affect RDW levels. The fact that these data of all patients were not available and that patients with these deficiencies were not excluded from the study can be shown as a limitation of our study. Being followed patients from a single-center and cross-sectional may be the other limitations of our study.

Strengths of our study are; the population was quite large, and patients with anemia were excluded from the study due to the effects on studied test parameters -especially RDW-, and some patients' test results of the last three months before death included to study. 
In conclusion, we found significant statistical associations of RDW, PLR, and NLR with mortality in patients with comorbidities who had become bedridden for various reasons. These tests, which are very simple, quick, and cheap, can predict deteriorating prognosis in both elderly and bedridden patients, and the necessary measures (such as hospitalization) can be life-saving for the patient. For this purpose, further research is necessary to establish RDW, PLR, and NLR as prognostic markers.

\section{REFERENCES}

1. Patel KV, Semba RD, Ferrucci $L$, et al. Red cell distribution width and mortality in older adults: a meta-analysis. J Gerontol A Biol Sci Med Sci 2009;65(3):258-65. (PMID:19880817).

2. Patel KV, Ferrucci L, Ershler WB, Longo DL, Guralnik JM. Red cell distribution width and the risk of death in middle-aged and older adults. Arch Intern Med 2009;169(5):515-23. (PMID:19273783).

3. Wang $X$, Zhang $G$, Jiang $X$, Zhu $H, L u ~ Z, X u ~ L$. Neutrophil to lymphocyte ratio in relation to risk of all-cause mortality and cardiovascular events among patients undergoing angiography or cardiac revascularization: a meta-analysis of observational studies. Atherosclerosis 2014;234(1):206-13. (PMID:24681815).

4. Yilmaz G, Sevinc C, Ustundag S, et al. The relationship between mean platelet volume and neutrophil/ lymphocyte ratio with inflammation and proteinuria in chronic kidney disease. Saudi J Kidney Dis Transpl 2017;28(1):90-4. (PMID:28098108).

5. Cataudella E, Giraffa CM, Di Marca S, et al. Neutrophil-to-lymphocyte ratio: an emerging marker predicting prognosis in elderly adults with community-acquired pneumonia. J Am Geriatr Soc 2017;65(8):1796-801. (PMID:28407209).

6. Tajarernmuang $P$, Phrommintikul A, Limsukon A, Pothirat $C$, Chittawatanarat $K$. The role of mean platelet volume as a predictor of mortality in critically ill patients: A systematic review and meta-analysis. Crit Care Res Pract 2016; Article ID:4370834:1-8. (PMID:26966574).

7. Yildirim MA, Seckin KD, Togrul C, et al. Roles of

\section{CONFLICT OF INTEREST}

None.

\section{FUNDING}

None. neutrophil/lymphocyte and platelet/lymphocyte ratios in the early diagnosis of malignant ovarian masses. Asian Pac J Cancer Prev 2014;15(16):6881-5. (PMID:25169540).

8. Cakmak E, Soylu S, Yonem O, Yilmaz A. Neutrophil-tolymphocyte ratio, platelet-to- lymphocyte ratio, and red blood cell distribution width as new biomarkers in patients with colorectal cancer. Erciyes Med J 2017;39(3):131-6. (DOI:10.5152/etd.2017.0051).

9. Janakiram NB, Rao CV. The Role of Inflammation in Colon Cancer, In: Aggarwal B, Sung B, Gupta S (Eds). Inflammation and Cancer. Advances in Experimental Medicine and Biology Series. Springer, Basel 2014;816, pp 25-52. (PMID:24818718).

10. Libby P, Ridker PM. Novel inflammatory markers of coronary risk: theory versus practice. Circulation 1999;100(11):1148-50. (PMID:10484532).

11. Plutzky J. Inflammatory pathways in atherosclerosis and acute coronary syndromes. Am J Cardiol 2001;88(8A):10K-15K. (PMID:11694213).

12. van Kimmenade RR, Mohammed $A A$, Uthamalingam S, van der Meer P, Felker GM, Januzzi Jr JL. Red blood cell distribution width and 1-year mortality in acute heart failure. Eur J Heart Fail 2010;12(2):129-36. (PMID:20026456).

13. Ozdogan HK, Karateke F, Ozyazıcı S, et al. The predictive value of red cell distribution width levels on mortality in intensive care patients with communityacquired intra-abdominal sepsis. Ulus Travma Acil Cerrahi Derg 2015;21(5):352-7. (PMID:26388271).

14. Kim SH, Yeon JH, Park KN, et al. The association of red cell distribution width and in-hospital mortality in older adults admitted to the emergency department. 
Scand J Trauma Resusc Emerg Med 2016;24, Article number: 81. (PMID:27267984).

15. Bozkurt D, Kilavuz A, Caferov N, Kose T, Akcicek F. Non-traditional mortality predictors for geriatric intensive care unit patients. Turkish Journal of Geriatrics, 2018;21(3):323-32. (DOI:10.31086/ tjgeri.2018344046).

16. Al-Kindi SG, Refaat $M$, Jayyousi A, Asaad $N$, Suwaidi JA, Khalil CA. Red cell distribution width is associated with all-cause and cardiovascular mortality in patients with diabetes. BioMed Res Int 2017; Article ID: 5843702. (PMID:29359154).

17. Skjelbakken T, Lappegard J, Ellingsen TS, et al. Red cell distribution width is associated with incident myocardial infarction in a general population: The Tromso Study. J Am Heart Assoc 2014;3(4):e001109. (PMID:25134681).

18. Alexander NI. Reference values of neutrophillymphocyte ratio, platelet- lymphocyte ratio and mean platelet volume in healthy adults in North Central Nigeria. J Blood Lymph 2016;6(1):1000143. (DOI:10.4172/2165-7831.1000143).

19. Lee JS, Kim NY, Na SH, Youn YH, Shin CS. Reference values of neutrophil- lymphocyte ratio, lymphocytemonocyte ratio, platelet-lymphocyte ratio, and mean platelet volume in healthy adults in South Korea. Medicine 2018;97(26):e11138. (PMID:29952958).
20. Oylumlu M, Yildiz A, Oylumlu M, et al. Plateletto-lymphocyte ratio is a predictor of in-hospital mortality patients with acute coronary syndrome. Anatol J Cardiol 2015;15(4):277-83. (PMID:25413224).

21. Wang $Y Q$, Zhi OJ, Wang $X Y$, Yue DS, Li K, Jiang RC. Prognostic value of combined platelet, fibrinogen, neutrophil to lymphocyte ratio and platelet to lymphocyte ratio in patients with lung adenosquamous cancer. Oncol Lett 2017;14(4):43318. (PMID:28943947).

22. Tamhane UU, Aneja S, Montgomery D, Rogers EK, Eagle KA, Gurm HS. Association between admission neutrophil to lymphocyte ratio and outcomes in patients with acute coronary syndrome. Am J Cardiol 2008;102(6):653-7. (PMID:18773982).

23. Liu $X$, Shen $Y$, Wang $H$, Ge Q, Fei A, Pan S. Prognostic significance of neutrophil-to- lymphocyte ratio in patients with sepsis: A prospective observational study. Mediators Inflamm 2016; Article ID:8191254. (PMID:27110067).

24. Hwang SY, Shin TG, Jo IJ, et al. Neutrophil-tolymphocyte ratio as a prognostic marker in criticallyill septic patients. Am J Emerg Med 2017;35(2):2349. (PMID:27806894).

25. Yoldas H, Karagoz I, Ogun MN, et al. Novel mortality markers for critically ill patients. J Intensive Care Med 2020;35(4):383-5. (PMID:29334832). 